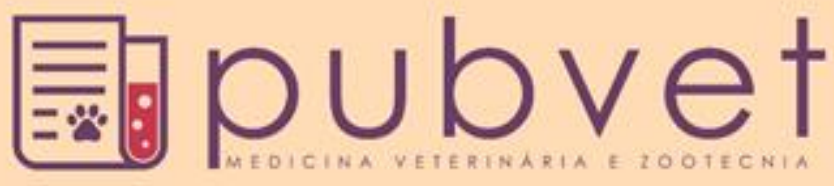

https://doi.org/10.31533/pubvet.v12n12a226.1-8

\title{
Ceratite ulcerativa corneana traumática em cão: tratamento com oxigenoterapia hiperbárica
}

\author{
Marcelo Fialho Mazzi ${ }^{1}$ \& Mariza D'Agostino Dias² ${ }^{2}$ \\ IMédico Veterinário CRMV-DF 0923 - Medicina Hiperbárica, Clínica Veterinária Planet Dog - Divisão MVH (Medicina Veterinária \\ Hiperbárica) Brasilia-DF, Brasil. \\ ${ }^{2}$ Médica Intensivista e Hiperbarista.Doutora em Ciências Médicas pela USP. Médica Supervisora do Grupo Oxigênio Hiperbárico de SP. \\ Autor para correspondência, E-mail: planetdogvet@terra.com.br
}

RESUMO. A ceratite ulcerativa de córnea é uma das causas mais comuns de doenças oculares que ocasionam a perda da visão nos cães. Sua etiologia compreende diversos tipos de trauma, produção lacrimal inadequada, lesões químicas e defeitos palpebrais dentre outras. A córnea é uma estrutura avascular, translúcida, composta histologicamente pelo epitélio, estroma, membrana descemet e endotélio. A profundidade que a lesão atinge nessas camadas, determina a intensidade dos sintomas como desconforto e dor ocular, fotofobia, blefaroespasmo, descarga ocular, epífora e perda da transparência corneana, culminando em sinéquia anterior, endoftalmite, colapso de câmara anterior, glaucoma e atrofia do corpo ciliar. A viabilidade de reparo tecidual, a técnica a ser empregada e o tempo previsto para a recuperação do tecido corneal estão intimamente ligados ao número de camadas comprometidas podendo oscilar de dias a meses. A oxigenoterapia hiperbárica (OHB) é uma terapia já utilizada no Brasil e no mundo todo em animais de experimentação em laboratórios, para várias patologias mostrando bons resultados, na rotina de clínica veterinária para pequenos animais sua proposta de utilização desponta como ferramenta diferencial e promissora, aumentando exponencialmente as chances de recuperação dos pacientes. A terapia consiste em manter o paciente no interior de uma câmara hermeticamente fechada, com suprimento controlado de oxigênio a 100\%, por períodos de tempo previamente estabelecidos e submetidos a níveis de pressão, acima da pressão atmosférica. A oxigenoterapia hiperbárica acelera o processo de cicatrização de lesões teciduais espontâneas ou traumáticas A escassez de relatos sobre utilização da oxigenoterapia hiperbárica no tratamento de úlceras de córnea justifica a descrição literária deste caso clínico, contribuindo assim para um maior esclarecimento de aspectos relacionados à fisiopatologia, diagnóstico e novas possibilidades de tratamento desta patologia na medicina veterinária e humana. O presente trabalho relata o caso de um canino macho da raça Pug de 3 anos com ceratite ulcerativa corneana traumática, tratado com oxigenoterapia hiperbárica, com rápida e completa cicatrização da lesão em 20 sessões.

Chaves: cicatrização, hiperbárico, oxigênio, úlcera, veterinária

\section{Traumatic corneal ulcerative keratitis in dogs: treatment with hyperbaric oxygen therapy}

ABSTRACT. Corneal ulcerative keratitis is one of the most common causes of eye disease that causes loss of vision in dogs. Its etiology includes several types of trauma, inadequate lacrimal production, chemical lesions and eyelid defects, among others. The cornea is a non-vascularized, translucent structure, histologically composed of the epithelium, stroma, descemet membrane and endothelium. The depth that the lesion reaches between these layers will determine the degree of symptoms such as discomfort and ocular pain, 
photophobia, blepharospasm, ocular discharge, epiphora and loss of corneal transparency, culminating in anterior synechia, endophthalmitis, previous chamber collapse, glaucoma and atrophy of the ciliary body. The feasibility of tissue repair, the technique to be employed and the time provided for the recovery of the corneal tissue are closely linked to the number of layers involved; ranging from days to months. Hyperbaric oxygen therapy is an innovative therapy for small animals that are kept inside a hermetically sealed chamber with $100 \%$ controlled oxygen supply for previously established periods of time and subjected to pressure levels above atmospheric pressure. Hyperbaric oxygen therapy has the potential to accelerate the wound healing process. The scarcity of reports on the use of hyperbaric oxygen therapy in the treatment of corneal ulcers justifies the literary description of this clinical case, thus contributing to a greater clarification of aspects related to pathophysiology, diagnosis and new possibilities of treatment of this pathology in veterinary and human medicine. This paper reports the case of a three year old male Pug dog with traumatic corneal ulcerative keratitis treated with hyperbaric oxygen therapy, with fast and completes healing in 20 treatments.

Keys: healing, hyperbaric, oxygen, ulcer, veterinary

\section{Ceratitis ulcerativa corneana traumática en perro: tratamiento con oxigenoterapia hiperbárica}

RESUMEN. La ceratitis ulcerativa de córnea es una de las causas más comunes de enfermedades oculares que ocasionan la pérdida de visión en los perros. Su etiología comprende diversos tipos de trauma, producción lagrimal inadecuada, lesiones químicas y defectos palpebrales entre otras. La córnea es una estructura avascular, translúcida, compuesta histológicamente por el epitelio, estroma, membrana descemet y endotelio. La profundidad que la lesión alcanza en estas capas determina la intensidad de los síntomas como incomodidad y dolor ocular, fotofobia, blefaroespasmo, descarga ocular, epífora y pérdida de la transparencia corneal, culminando en la sinéquia anterior, endoftalmitis, colapso de cámara anterior, glaucoma y atrofia del aparato ciliar. La viabilidad de reparación del tejido, la técnica a emplearse y el tiempo previsto para la recuperación del tejido corneal están íntimamente ligados al número de capas comprometidas pudiendo oscilar de días a meses. La oxigenoterapia hiperbárica $(\mathrm{OHB})$ es una terapia ya utilizada en Brasil y en todo el mundo en animales de experimentación en laboratorios, para varias patologías mostrando buenos resultados, en la rutina de clínica veterinaria para pequeños animales su propuesta de utilización despunta como herramienta diferencial y prometedora, aumentando exponencialmente las posibilidades de recuperación de los pacientes. La terapia consiste en mantener al paciente dentro de una cámara herméticamente cerrada, con un suministro controlado de oxígeno al $100 \%$, por períodos de tiempo previamente establecidos y sometidos a niveles de presión, por encima de la presión atmosférica. La escasez de relatos sobre utilización de la oxigenoterapia hiperbárica en el tratamiento de úlceras de córnea justifica la descripción literaria de este caso clínico, contribuyendo así a una mayor aclaración de aspectos relacionados a la fisiopatología, diagnóstico y nuevas posibilidades de tratamiento de esta patología en la medicina veterinaria y humana. El presente trabajo relata el caso de un canino macho de la raza Pug de 3 años con ceratitis ulcerativa corneana traumática, tratado con oxigenoterapia hiperbárica, con rápida y completa cicatrización de la lesión en 20 sesiones.

Palabras clave: cicatrización, hiperbárica, oxígeno, úlcera, veterinaria

\section{Introdução}

Boevé et al. (2009) consideram que o olho é o órgão sensorial mais complexo do corpo dos vertebrados, sendo a córnea, a região mais anterior e que atua como uma barreira física e impermeável entre o olho e o ambiente. Konrade et al. (2012) conceituaram a córnea como uma estrutura transparente, com a capacidade de 70 a $80 \%$ do poder de refração total do olho. Anatomicamente, Slatter (2005) descreve a córnea como o segmento mais anterior do olho, pertencendo à túnica fibrosa 
externa. Sendo quase circular e como o bulbo, de forma geral, tem suas dimensões variando entre as raças. O diâmetro oscila de $12.5 \mathrm{~mm}$ a $17 \mathrm{~mm}$. O raio de curvatura tendo aproximadamente de 8 $\mathrm{mm}$ e sua espessura variando de 0,6 a $0,95 \mathrm{~mm}$. Helper (1989) classifica a córnea canina como composta por quatro camadas distintas, sendo elas; o epitélio $(0,08 \mathrm{~mm})$, estroma $(0,5-0,6 \mathrm{~mm})$, a membrana descemet e o endotélio (Figura 1).

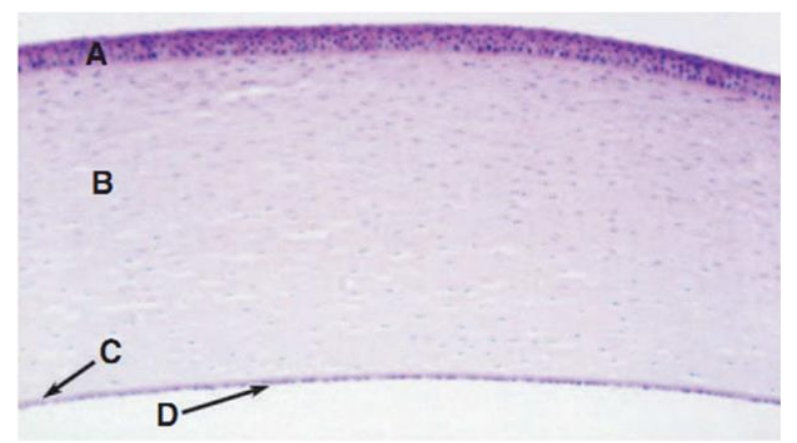

Figura 1. Estrutura da córnea; A, Epitélio; B, Estroma; C, Membrana de Descemet; D, Endotélio. Fonte: Adaptado de Maggs (2008).

Em sua obra, Slatter (2005) disserta sobre a composição histológica da córnea, sendo considerado o epitélio como simples e básico de membrana basal, células epiteliais basais, portanto uma continuação da conjuntiva bulbar; o estroma composto por fibrócitos, ceratinócitos, colágeno e substância fundamental, constituindo $90 \%$ da substância corneana. A membrana descemet é constituída segundo Brooks \& Ollivier (2004) por colágeno dos tipos I, III, IV, V, VI VIII, laminina e fibronectina e descrita por Maggs (2008) e Martin (2010) como muito elástica, mas que pode fragmentar-se em casos de glaucoma avançado, em lesões penetrantes ou úlceras. O endotélio, camada mais interna da córnea é conceituado por Arndt et al. (2001) como relativamente permeável, possibilitando assim a passagem de água e de outras moléculas, garantindo assim a nutrição da mesma. A morfologia do endotélio corneal pode ser alterada por ocorrência de distrofias corneais, ceratocones, glaucomas, uveítes ou traumas oculares (Franzen et al. 2010). A córnea intacta é muito resistente a infecções, mas qualquer descontinuidade do seu epitélio permite a invasão corneana e multiplicação de microrganismos (Startup 1984). Sua transparência e curvatura são mantidas pelas características anatômicas e celulares (Helper 1989); e baseia-se num arranjo altamente organizado de fibrilas de colágeno no estroma, na ausência de vasos sanguíneos e de pigmento, no controle do teor de água e na presença de uma superfície não queratinizada (Laus et al. 2002). Sob a ótica vascular, a córnea é um tecido avascular e recebe sua nutrição por um processo de diálise pelos vasos do plexo perilimbar e em menor quantidade pelo humor aquoso e lágrimas (Slatter 2005).

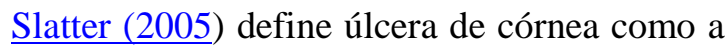
perda de parte do epitélio e uma quantidade de estroma, tornando-se lesões crônicas e sendo uma das doenças oculares mais comuns em cães, levando frequentemente à perda da visão. As primeiras lesões são visíveis como zonas brancoacinzentadas de várias formas, coincidindo com as zonas de epitélio alterado. São intensamente dolorosas devido a inúmeras terminações nervosas sensoriais do epitélio corneano (Madany 2006). De acordo com Kim et al. (2009), as úlceras podem ser classificadas de acordo com o comprometimento das camadas corneanas em: superficial, estromal profunda e descemetocele. Nasisse (1985) elucida que quando a invasão microbiana não é rapidamente contida, ocorrem processos inflamatórios crônicos, levando a uma cascata de liberação enzimática que rapidamente degrada o colágeno estromal, podendo levar a formação de "melting" e perfuração ocular. Caso não ocorra perfuração, a cicatriz corneana pode limitar a visão devido à presença de denso tecido cicatricial substituindo as lamelas de colágeno. Kern (1990) classifica o processo de reorganização como lento e que raramente permite a restauração da transparência da córnea, tendo como sequelas comuns após ulceração corneal a névoa, mácula e o leucoma, que consistem em vários graus de opacidade corneal. Sendo: névoa - opacidade leve, mácula - opacidade cinza bem definida e leucoma - opacidade densa e branca. Algumas raças, como sugerem Galera et al. (2009), são apontadas como mais predispostas às úlceras de córnea, dentre as quais se enfatiza as braquicefálicas podendo, entretanto, ocorrer em qualquer raça ou idade.

A oxigenoterapia hiperbárica é conceituada pelo ECHM - European Committee for Hyperbaric Medicine, como uma intervenção terapêutica, na qual os pacientes inalam oxigênio puro (100\%) a uma pressão superior à pressão do nível do mar (1 atmosfera técnica absoluta ATA), dentro de uma câmara hiperbárica. O modo de ação desta terapia é descrito por Thom (2009) como complexo, pois é resultado de uma série de 
mecanismos fisiológicos e farmacológicos, dependentes da elevação da pressão parcial do oxigênio e da pressão hidrostática. A oxigenoterapia hiperbárica tem por base várias leis da física, das quais Mathieu (2006) destaca: Lei Boyle-Mariotte; Princípio de Pascal, Lei de Henry, Lei de Dalton e Leis de Fick.

$\mathrm{O}$ efeito imediato da oxigenoterapia hiperbárica é a hiperoxigenação que resulta do aumento do oxigênio dissolvido no plasma; o qual é diretamente proporcional à pressão parcial do oxigênio inalado Bassett \& Bennett (1977). Um dos efeitos da OHB é o da melhoria da perfusão microvascular, provavelmente relacionado com um estímulo á síntese de óxido nitroso pelo oxigênio hiperbárico (Thom et al. 2003).

\section{Relato de caso}

Cão, macho, raça Pug, três anos, com $12 \mathrm{~kg}$ foi atendido na clínica veterinária Planet DogBrasília-DF, Divisão de MVH - Medicina Veterinária Hiperbárica. Proprietário relatou que havia deixado o paciente com outro cão, que pela manhã notou inapetência, inquietação e que o paciente não conseguia abrir o olho direito, que também apresentava secreção lacrimal intensa. Ao exame físico, o animal apresentava os parâmetros vitais dentro da normalidade para a espécie. Ao exame oftálmico, observou-se, hipersensibilidade local, hiperemia conjuntival, secreção mucóide, epífora, abaulamento e edema da córnea, fotofobia e irregularidade da superfície da córnea do olho afetado. A coloração pela fluoresceína sódica $2 \%$ evidenciou a presença de uma úlcera estromal profunda no olho direito. O exame de fundo de olho não foi possível devido à opacidade corneana. Não havia qualquer tipo de alteração no olho esquerdo, estando apenas o olho direito comprometido (Figura 2).

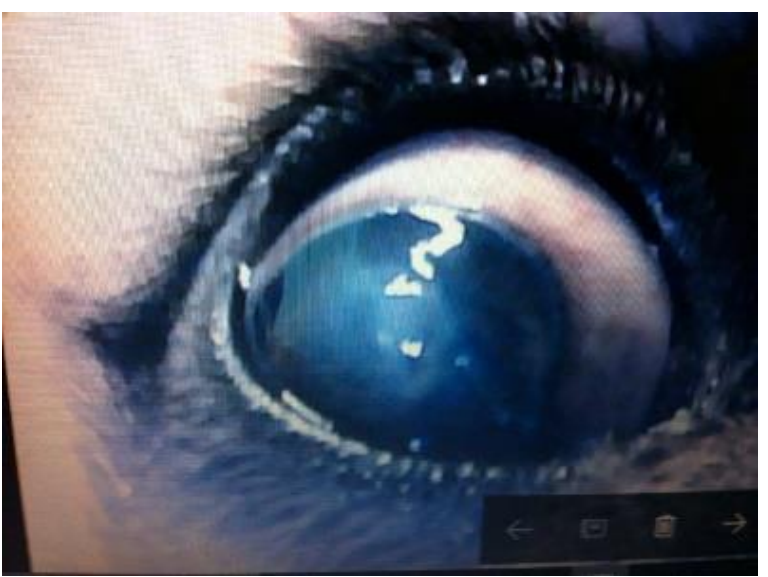

Figura 2. Fotografia do olho direito lesionado. Fonte: $\underline{\text { Mazzi }}$ \& D’Agostino (2018).
$\mathrm{O}$ paciente foi mantido em ambiente controlado, com colar elisabetano. Efetuou-se a limpeza do olho com água bidestilada (BID); foi instaurado o protocolo: Meloxitabs ${ }^{\circledR} 0,5 \mathrm{mg} .1$ comprimido ao dia durante nove dias; colírio Ciprovet ${ }^{\circledR}, 1$ gota $2 \mathrm{x}$ ao dia por 20 dias. Concomitantemente ao tratamento convencional, foram efetuadas sessões diárias de oxigenoterapia hiperbárica em câmara hiperbárica (Figura 3).

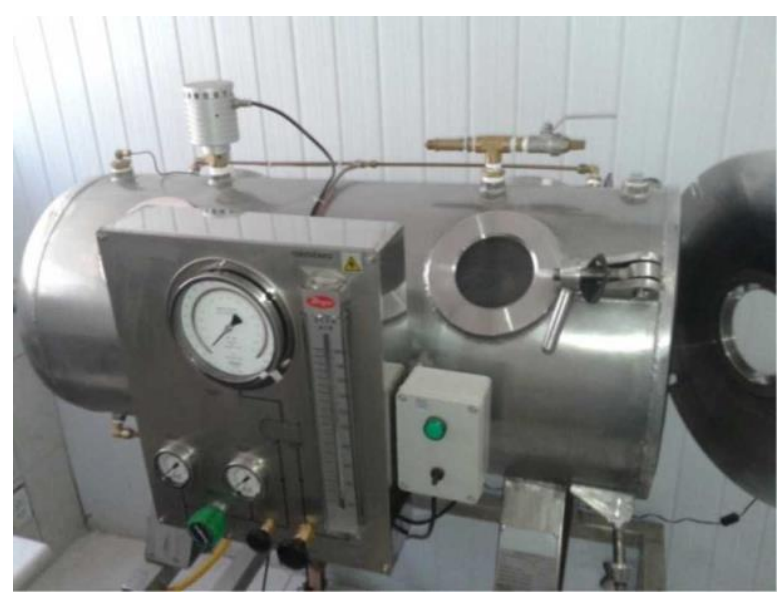

Figura 3. Fotografia da câmara hiperbárica tipo monoplace. Fonte: Mazzi (2018)

O protocolo das sessões de oxigenoterapia hiperbárica foi estabelecido no parâmetro de uma sessão a cada 24 horas. Não houve necessidade de sedação; o tempo total de realização na ordem de 90 (noventa) minutos, entre as fases de compressão/fundo/descompressão e a profundidade de 50 "pés de água do mar", portanto a pressão total de 2,5 ATA (Atmosfera Técnica Absoluta). Foram realizados registros de imagem para a avaliação clínica e submetidas à análise morfométrica em software analítico microscópio digital SuperEye $2{ }^{\circledR}$ (Figura 4), para determinação da área compreendida da lesão e sua evolução. A mensuração da lesão foi realizada de forma prévia às sessões de oxigenoterapia hiperbárica; e tiveram seus padrões estabelecidos em 2 eixos (longitudinal e horizontal) à lesão, tomando por base a área mais central e densa da lesão, desprezando-se as áreas adjacentes, caracterizadas como névoa. $\mathrm{O}$ presente estudo considerou o quadro apresentado pelo paciente como sendo uma ceratite ulcerativa com comprometimento estromal pela gravidade dos sintomas apresentados. 


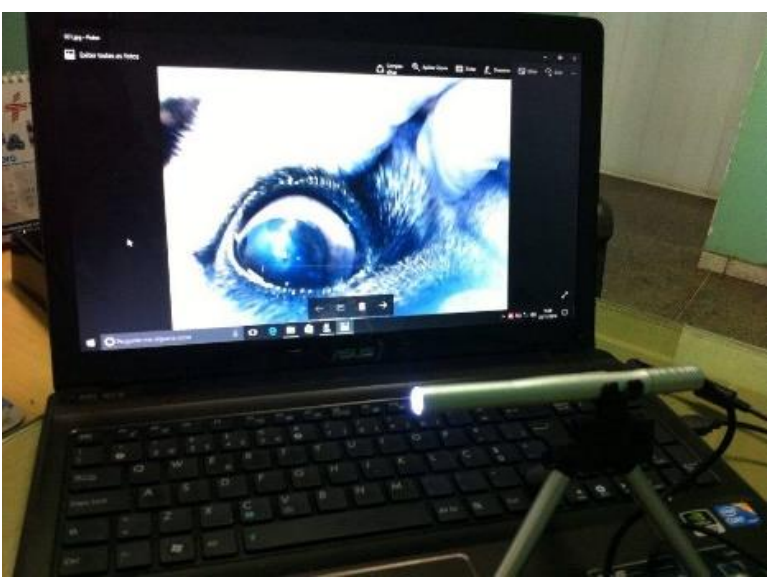

Figura 4. Microscópio digital SuperEye 2. Fonte: Mazzi \& D’Agostino (2018).

\section{Resultados}

A análise morfométrica da lesão através do softwear SuperEye $2 \circledR$, obteve na primeira sessão o eixo longitudinal com valor de $0,1061 \mathrm{~mm}$ e o eixo horizontal da lesão com $0,0751 \mathrm{~mm}$. As mensurações subsequentes foram entabuladas (Tabela1) e gerado o (Gráfico 1) para determinação da evolução da lesão. Ao término da $20^{\mathrm{a}}$ sessão de oxigenoterapia hiperbárica, o eixo longitudinal apresentava $0,0120 \mathrm{~mm}$ e o eixo horizontal da lesão com $0,0082 \mathrm{~mm}$.

Ao final do tratamento na $20^{\circ}$ sessão, a córnea teve sua curvatura restabelecida, havendo mínima sequela cicatricial da lesão em comparação ao primeiro momento (Figura 5). Durante o tratamento, o eixo longitudinal da lesão alcançou o percentual de retrocesso de $88,68 \%$, enquanto o eixo horizontal obteve o percentual de $89,08 \%$. A retração das bordas da lesão apresentou-se progressiva, com evidente remodelação tecidual normotrófica sem prejuízo à acuidade visual do paciente.

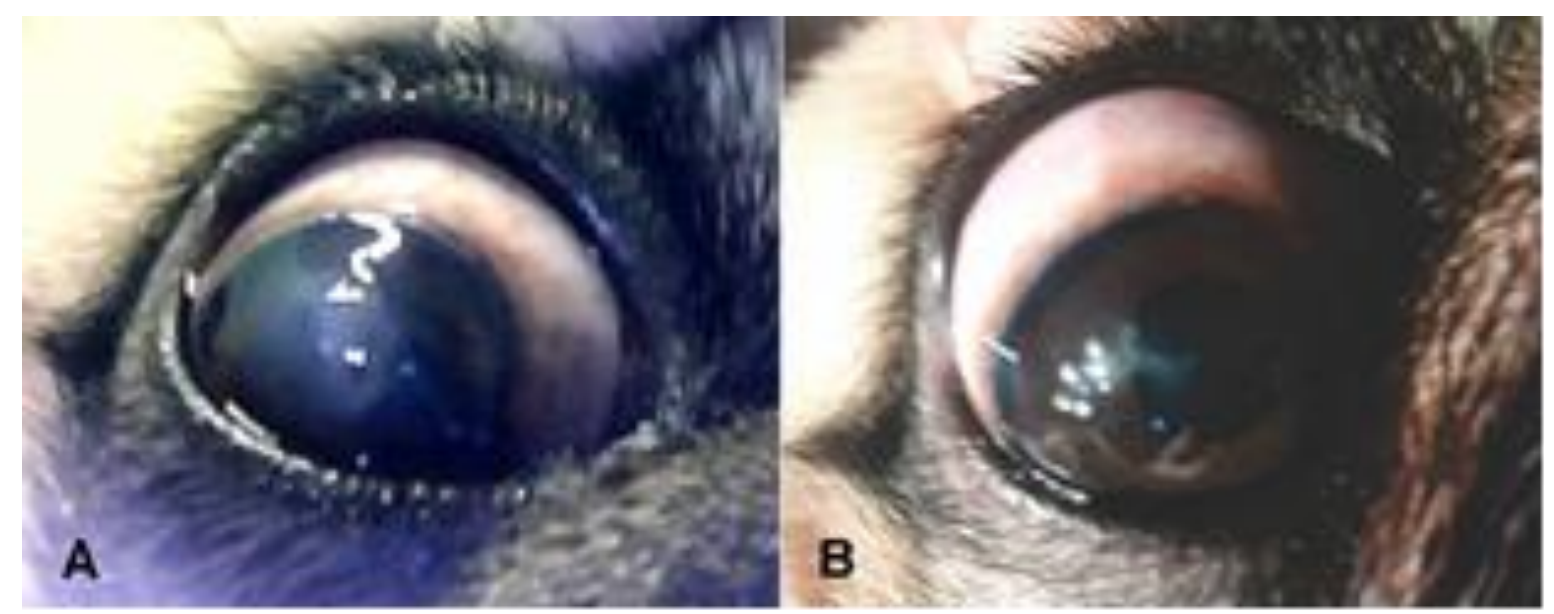

Figura 5. Fotografia do olho direito na $1^{\mathrm{a}}$ sessão (A) e após a $20^{\mathrm{a}}$ sessão oxigenoterapia hiperbárica (B). Fonte: Mazzi \& D’Agostino (2018).

Tabela 1. Mensuração da extensão da lesão

\begin{tabular}{|c|c|c|c|c|c|}
\hline Dia da Lesão & Eixo L (mm) & Eixo H (mm) & Dia da Lesão & Eixo L $(\mathrm{mm})$ & Eixo $\mathrm{H}(\mathrm{mm})$ \\
\hline $1^{\circ} \mathrm{dia}$ & $0,1061 \mathrm{~mm}$ & $0,0751 \mathrm{~mm}$ & $11^{\circ}$ dia & $0,0319 \mathrm{~mm}$ & $0,0147 \mathrm{~mm}$ \\
\hline $2^{\circ} \mathrm{dia}$ & $0,0853 \mathrm{~mm}$ & $0,0677 \mathrm{~mm}$ & $12^{\circ} \mathrm{dia}$ & $0,0279 \mathrm{~mm}$ & $0,0141 \mathrm{~mm}$ \\
\hline $3^{\circ}$ dia & $0,0612 \mathrm{~mm}$ & $0,0383 \mathrm{~mm}$ & $13^{\circ} \mathrm{dia}$ & $0,0250 \mathrm{~mm}$ & $0,0166 \mathrm{~mm}$ \\
\hline $4^{\circ}$ dia & $0,0429 \mathrm{~mm}$ & $0,0364 \mathrm{~mm}$ & $14^{\circ} \mathrm{dia}$ & $0,0270 \mathrm{~mm}$ & $0,0198 \mathrm{~mm}$ \\
\hline $5^{\circ}$ dia & $0,0356 \mathrm{~mm}$ & $0,0388 \mathrm{~mm}$ & $15^{\circ} \mathrm{dia}$ & $0,0213 \mathrm{~mm}$ & $0,0115 \mathrm{~mm}$ \\
\hline $6^{\circ}$ dia & $0,0239 \mathrm{~mm}$ & $0,0193 \mathrm{~mm}$ & $16^{\circ}$ dia & $0,0281 \mathrm{~mm}$ & $0,0174 \mathrm{~mm}$ \\
\hline $7^{\circ}$ dia & $0,0277 \mathrm{~mm}$ & $0,0224 \mathrm{~mm}$ & $17^{\circ} \mathrm{dia}$ & $0,0214 \mathrm{~mm}$ & $0,0131 \mathrm{~mm}$ \\
\hline $8^{\circ}$ dia & $0,0378 \mathrm{~mm}$ & $0,0206 \mathrm{~mm}$ & $18^{\circ} \mathrm{dia}$ & $0,0255 \mathrm{~mm}$ & $0,0151 \mathrm{~mm}$ \\
\hline $9^{\circ}$ dia & $0,0203 \mathrm{~mm}$ & $0,0166 \mathrm{~mm}$ & $19^{\circ} \mathrm{dia}$ & $0,0217 \mathrm{~mm}$ & $0,0133 \mathrm{~mm}$ \\
\hline $10^{\circ} \mathrm{dia}$ & $0,0395 \mathrm{~mm}$ & $0,0219 \mathrm{~mm}$ & $20^{\circ} \mathrm{dia}$ & $0,0120 \mathrm{~mm}$ & $0,0082 \mathrm{~mm}$ \\
\hline
\end{tabular}

Fonte: Mazzi \& D’Agostino (2018). 


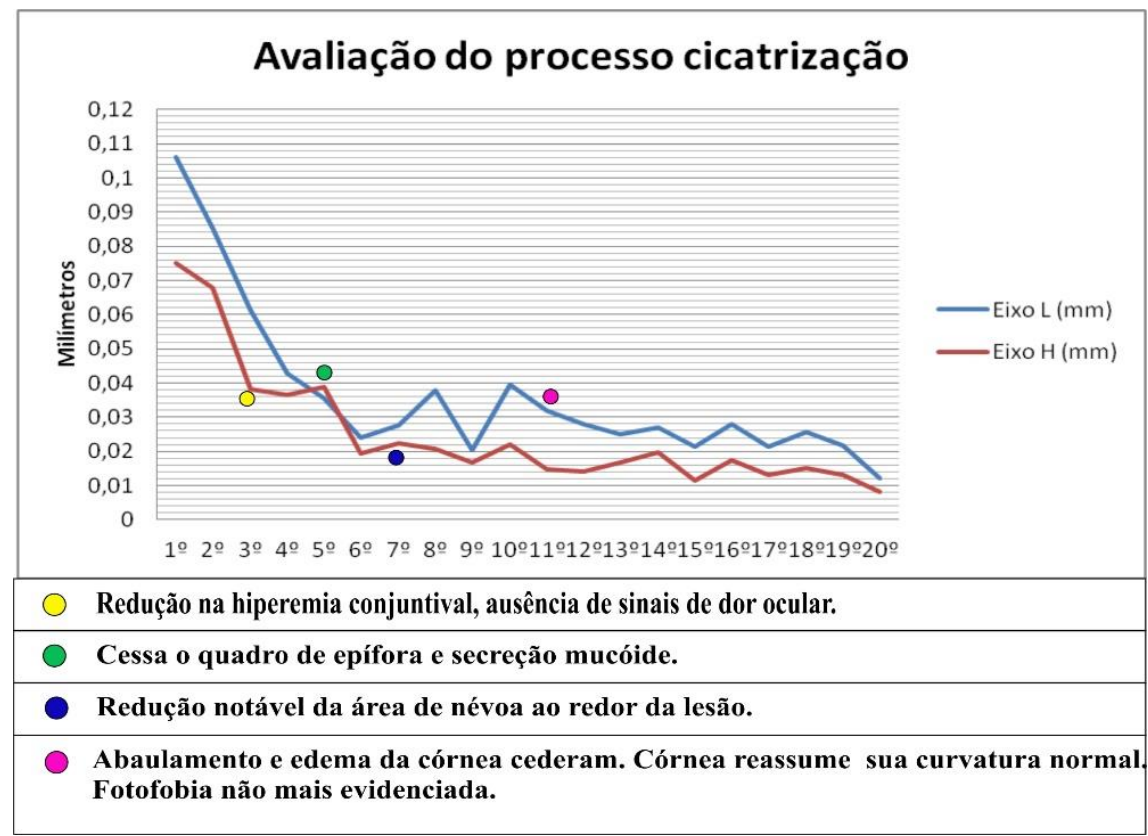

Gráfico 1. Avaliação processo de cicatrização. Fonte: Mazzi \& D’Agostino (2018).

\section{Discussão}

Oliveira \& Dias (2012) destacam que a cicatrização é um evento sistêmico, que abrange uma gama de fatores que precisam interagir entre si para que haja uma evolução de forma eficiente. Esses fatores, bem como as interações existentes entre eles, precisam ser bem elucidados para que os profissionais possam interferir no processo, tendo em vista que a aceleração do processo de cicatrização é muitas vezes um dos principais objetivos terapêuticos na rotina clínica. Como afirmam Kim et al. (2009), as ceratites ulcerativas constituem as doenças oculares mais comumente encontradas na oftalmologia veterinária. Entretanto, apesar de representarem uma ameaça à visão dos animais domésticos, elas são passíveis de tratamento clínico, cirúrgico e/ou ambos.

A fisiopatogenia das úlceras, como propõem Vongsakul et al. (2009) é acompanhada de uma inflamação prolongada, a qual prejudica as células-tronco da córnea e da membrana epitelial basal, resultando em neovascularização, cicatrizes corneanas e comprometimento da visão. Além disso, ressaltam Prado et al. (2006) e Vanore et al. (2007) que as células inflamatórias, fibroblastos, ceratinócitos, micro-organismos e células epiteliais produzem colagenases e outras enzimas proteolíticas, as quais podem causar progressiva degradação do colágeno estromal corneano, com o risco de perfuração. Do ponto de vista oftálmico Sharifipour et al. (2011) conceituam que as lesões oculares são emergências oftalmológicas cuja extensão de gravidade depende da isquemia das stem cells do limbo, que são a fonte da regeneração epitelial da córnea. Afirmando ainda que o uso da oxigenoterapia hiperbárica tem um efeito positivo na regeneração da isquemia do limbo, acelerando a epitelização, aumentando a transparência da córnea e melhorando a acuidade visual, ao mesmo tempo em que reduz a possibilidade de complicações. No entanto, Sharma et al. (2018) ponderam que a experiência com o uso de terapia hiperbárica nestas situações está ainda limitada quase exclusivamente a modelos animais, até se estabelecerem protocolos de tratamento.

Kern (1990) e Slatter (2005) igualmente consideram que a cicatrização de uma ferida na córnea obedece a uma sequência de eventos organizados e cronologicamente estabelecidos, e que ao longo deste processo podem ocorrer inflamação crônica, neovascularização e defeitos epiteliais recorrentes. Lesões apenas superficiais que não afetem a membrana basal do epitélio terão a arquitetura normal do epitélio restaurada em 5 a 7 dias (Kern 1990). Se a membrana basal do epitélio for danificada, deverá primeiramente ser recuperada, podendo demorar até 6 semanas para ser restaurada. Caso a lesão atinja a profundidade do estroma corneano, seu estado metabólico relativamente inativo irá propiciar uma cicatrização mais complexa e demorada. O ferimento será primeiramente coberto por um tampão de fibrina; leucócitos chegam através do filme lacrimal e a partir de migração estromal; os fibroblastos convertidos a partir de ceratócitos 
participarão na organização e fortalecimento da lesão pelos próximos 3 a 6 meses. Quando ocorre perfuração da membrana descemet, o processo de cicatrização tende a ser ainda mais longo e complicado (Nasisse 1985; Slatter 2005).

Rabelo (2012) afirma em sua obra que os efeitos indiretos da hiperoxigenação são: vasoconstricção periférica, aumento da produção de fibroblastos, neovascularização, inibição e inativação de toxinas e sinergismo com antibióticos, corroborando assim para uma lógica na escolha desta terapia como alternativa na conduta clínica do tratamento de ceratite ulcerativa traumática em cães.

\section{Conclusão}

As úlceras de córnea são de casuística elevada e ocorrem com frequência nos cães. São na grande maioria das vezes de origem traumática, podendo ocorrer também por problemas relacionados a conformação racial, frequente nas raças braquicefálicas.

$\mathrm{Na}$ análise das medidas sequenciais, averiguou-se um peculiar ritmo no processo de cicatrização, onde as bordas da lesão realizaram movimentos alternados centrípetos e centrífugos rumo ao centro da lesão, sugerindo um padrão cicatricial em saltos, o que converge com achados de literatura sobre o "efeito On-Off" proporcionado pela oxigenoterapia hiperbárica; observação esta que necessita maiores estudos. A oxigenoterapia hiperbárica já possui aplicações estabelecidas no campo oftalmológico; como o tratamento da oclusão da artéria central da retina, nas infecções oculares como a mucormicose rinoorbito-cerebral, na retinopatia e neuropatia ótica por radiação e na retinite pigmentar. Sobre o uso da OHB no tratamento de ceratite ulcerativa traumática da córnea não foram encontrados estudos comparativos e nem descrição de casos publicados na literatura. Desta forma, o norteamento dos protocolos de tratamento neste caso específico, mantêm-se abertos, tendo por base única a resposta positiva às aplicações de forma continua até que se promova a cicatrização ou até que a lesão deixe de responder; sendo mantidos nos parâmetros de sessões convencionais, com intervalo de 24 horas entre cada tratamento, devido à gravidade do caso e à necessidade de uma cicatrização mais rápida, reduzindo assim a possibilidade de complicações tais como infecções e ou perfurações. Considerando seu efeito benéfico já conhecido em muitos tipos de úlceras, aliado à constatação que o processo de cicatrização e redução desta lesão no cão da raça Pug ocorreu de forma linear e de aspecto normotrófico; mantendo-se a acuidade visual do paciente, em um período de tempo consideravelmente menor de 20 dias; quando comparado ao tempo esperado com o tratamento clínico convencional de até seis meses; reforça-se a indicação de sua utilização e a importância do desenvolvimento de estudos que extrapolem o tema para outras raças e espécies sobre a atuação da oxigenoterapia hiperbárica aliada à oftalmologia veterinária e humana.

\section{Referências bibliográficas}

Arndt C., Reese S. \& Köstlin R. 2001. Preservation of canine and feline corneoscleral tissue in Optisol ${ }^{\circledR}$ GS. Veterinary ophthalmology 4, 175-182.

Bassett B.E. \& Bennett P.B. 1977. Introduction to the physical and physiological bases of hyperbaric therapy. In: Hyperbaric oxygen therapy (eds. by Davis JE \& T.K. H), pp. 1124. Undersea Medical Society, Bethesda Md.

Boevé M.H., Stades F.C. \& DjajadiningratLaanen S.C. 2009. Eyes. In: Medical History and Physical Examination in Companion Animals (eds. by Rijnberk A \& Van Sluijs FJ), pp. 175-201. Ed Elsevier.

Brooks D.E. \& Ollivier F.J. 2004. Matrix metalloproteinase inhibition in corneal ulceration. Veterinary Clinics: Small Animal Practice 34, 611-622.

Franzen A.A., Pigatto J.A.T., Abib F.C., Albuquerque L. \& Laus J.L. 2010. Use of specular microscopy to determine corneal endothelial cell morphology and morphometry in enucleated cat eyes. Veterinary ophthalmology 13, 222-226.

Galera P.D., Laus J.L. \& Oriá A.P. 2009. Afecções da túnica fibrosa. In: Oftalmologia Clínica e Cirúrgica em Cães e em Gatos (ed. by Laus JL), pp. 69-96. Editora Roca, São Paulo, Brasil.

Helper J.C. (1989. Diseases and surgery of the cornea and sclera. In: Magrane's canine ophthalmology (eds. by Lea \& Febiger), pp. 102-149, Philadelphia, USA.

Kern T.J. (1990. Ulcerative keratitis. Veterinary Clinics of North America: Small Animal Practice 2, 643-665.

Kim J.Y., Won H.-J. \& Jeong S. 2009. A retrospective study of ulcerative keratitis in 32 
dogs. International Journal of Applied Research in Veterinary Medicine 7, 27-31.

Konrade K.A., Hoffman A.R., Ramey K.L., Goldenberg R.B. \& Lehenbauer T.W. 2012. Refractive states of eyes and associations between ametropia and age, breed, and axial globe length in domestic cats. American journal of veterinary research 73, 279-284.

Laus J.L., Santos C., Talieri I.C., Oriá A.P. \& Bechara G.H. 2002. Combined corneal lipid and calcium degeneration in a dog with hyperadrenocorticism: a case report. Veterinary ophthalmology 5, 61-64.

Madany J. 2006. Corneal dystrophies and degenerations in dogs. Annales Universitatis Mariae Curie-Sklodowa 41, 45-54.

Maggs D.J. 2008. Cornea and sclera. In: Slatter's fundamentals of veterinary ophthalmology (eds. by Maggs DJ, Miller PE \& Ofri R), pp. 175-202. Ed. Saunders, USA.

Martin C.L. 2010. Cornea and sclera. In: Ophthalmic disease in veterinary medicine (ed. by Martin CL), pp. 241-298. Manson Publishing, USA.

Mathieu D. 2006. Handbook on hyperbaric medicine. Ed Springer, Dordrecht.

Mazzi, M. F. 2018. A utilização da oxigenoterapia hiperbárica no tratamento de fasceíte necrotizante do prepúcio de um cão idoso. Pubvet, 12(7), 1-7

Nasisse M.P. 1985. Canine ulcerative keratitis. The Compendium on Continuing Education for the Practicing Veterinarian 7, 686-698.

Oliveira I.V.P.M. \& Dias R.V.C. 2012. Cicatrização de feridas: fases e fatores de influência. Acta Veterinaria Brasilica 6, 267271.

Prado M.R., Brito E.H.S., Girão M.D., Sidrim J.J.C. \& Rocha M.F.G. 2006. Identification and antimicrobial susceptibility of bacteria isolated from corneal ulcers of dogs. Arquivo Brasileiro de Medicina Veterinária e Zootecnia 58, 10241029.

Rabelo R. 2012. Emergências em pequenos animais: Condutas clínicas e cirúrgicas no paciente grave. Elsevier Brasil, Rio de Janeiro.
Sharifipour F., Baradaran-Rafii A., Idani E., Zamani M. \& Bonyadi M.H.J. 2011. Oxygen therapy for acute ocular chemical or thermal burns: a pilot study. American journal of ophthalmology 151, 823-828.

Sharma N., Kaur M., Agarwal T., Sangwan V.S. \& Vajpayee R.B. 2018. Treatment of acute ocular chemical burns. Survey of ophthalmology 63, 214-235.

Slatter D. 2005. Córnea e Esclera. In: Fundamentos em Oftalmologia Veterinária (ed. by Slatter D), pp. 283-338. Roca, São Paulo, Brasil.

Startup F.G. (1984. Corneal ulceration in the dog. Journal of Small Animal Practice 25, 737-752.

Thom S.R. 2009. Oxidative stress is fundamental to hyperbaric oxygen therapy. Journal of Applied Physiology 106, 988-995.

Thom S.R., Fisher D., Zhang J., Bhopale V.M., Ohnishi S.T., Kotake Y., Ohnishi T. \& Buerk D.G. 2003. Stimulation of perivascular nitric oxide synthesis by oxygen. American Journal of Physiology-Heart and Circulatory Physiology 284, H1230-H1239.

Vanore M., Chahory S., Payen G. \& Clerc B. 2007. Surgical repair of deep melting ulcers with porcine small intestinal submucosa (SIS) graft in dogs and cats. Veterinary ophthalmology 10, 93-99.

Vongsakul S., Tuntivanich P., Sirivaidyapong S. \& Kalpravidh M. 2009. Canine amniotic membrane transplantation for ocular surface reconstruction of created deep corneal ulcers in dogs. Thai Journal of Veterinary Medicine 39, 133-142.

Recebido: 22 setembro, 2018

Aprovado: 31 outubro, 2018.

Publicado: 26 dezembro, 2018.

Licenciamento: Este artigo é publicado na modalidade Acesso Aberto sob a licença Creative Commons Atribuição 4.0 (CC-BY 4.0), a qual permite uso irrestrito, distribuição, reprodução em qualquer meio, desde que o autor e a fonte sejam devidamente creditados. 